\title{
UNA MIRADA TERRIBLE: USOS TEXTUALS I ICONOGRÀFICS DE MEDUSA EN ÈPOCA IMPERIAL*
}

\author{
PILAR GÓMEZ CARDÓ \\ Universitat de Barcelona \\ pgomez@ub.edu \\ ORCID: 0000-0001-6560-2836
}

RESUM

En la literatura grega d'època imperial romana els mites són encara un element important en la construcció del discurs narratiu. En aquesta literatura sovintegen les referències a obres artístiques perquè, en l'època de la Segona Sofística, l'art també revela cultura, forma part de la paideia, de manera que les obres d'art interessen perquè serveixen de suport a la història, al mite, i, per tant, són alhora senyal identitari de la tradició grega que nodreix la creació literària en els primers segles de l'Imperi. En tal context, aquest treball se centra en un mite concret, el de Medusa, amb l'objectiu d'acarar textos d'autors del segle II dC amb determinades manifestacions artístiques coetànies per tal d'examinar la funció del mite, tant en el relat textual com en la iconografia, i provar de trobar-ne punts en comú o elements de divergència.

PARAULES CLAU: Medusa, Segona Sofística, mite, text, imatge, iconografia.

\section{A TERRIBLE GAZE: TEXTUAL AND ICONOGRAPHIC USE OF MEDUSA DURING THE IMPERIAL PERIOD}

\section{ABSTRACT}

In the Greek literature of the Roman period, myths are still an important tool for the construction of narrative discourse. Artistic works are often referred to in literature because, during the Second Sophistic, art - as part of paideia - implied culture. Therefore, artworks were highly considered, since they were the graphic support of history and myth. Hence, they became a recognisable sign of the Greek tradition that nourished literary creation in the first centuries of the Roman Empire. Bearing this context in mind, this paper focuses on a specific myth - that of Medusa - and aims to compare texts written in the second century AD with contemporary artistic manifestations in order to examine the function of this myth, both in textual and iconographic narratives, and try to find the similarities and differences between them.

KEYWORDS: Medusa, Second Sophistic, myth, text, image, iconography.

\section{INTRODUCCIÓ}

El mite va ser un component fonamental de la literatura grega, ja des del seu naixement -com mostren els poemes homèrics-, que es va mantenir viu al llarg de la seva història en els diversos períodes i gèneres literaris. En aquest sentit, la

\footnotetext{
* Aquest treball s'inclou en el projecte "Arte de la palabra y representación de la imagen en el pensamiento y la literatura griega de época imperial: Plutarco, Dión Crisóstomo, Luciano, Filóstrato", dirigit per la professora F. Mestre Roca i finançat pel Ministerio de Economía y Competitividad (FFI2016-77969-P).
} 
literatura grega d'època romana no n'és cap excepció, i en són una prova obres, en aparença, tan distintes com els diàlegs de Llucià o les Imagines de Filòstrat, $\mathrm{o}$ si hom té en compte l'ús que en fan Plutarc o Dió de Prusa, per esmentar només alguns autors grecs d'aquest període. El segle II dC és el moment àlgid de la

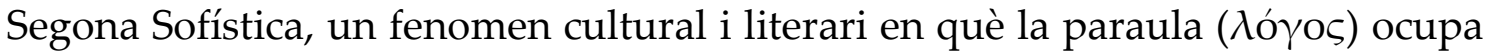
un espai nuclear, atès que la retòrica domina en la formació i educació dels joves de l'Imperi, també en la creació literària, i transcendeix l'àmbit de la pràctica oratòria i de l'escola. D'altra banda, no és estrany trobar en l'obra dels autors d'aquesta centúria nombroses referències a la creació artística, plàstica, perquè, en època imperial romana, l'art també revela cultura ( $\pi \alpha \iota \delta \varepsilon i ́ \alpha)$, de manera que les obres d'art interessen en la mesura en què també expliquen la història, els mites, i, en conseqüència, són alhora signes identificadors de la tradició grega.

Aquest treball remet al mite de la Gòrgona Medusa -ben conegut tant en la literatura grega, des de la poesia èpica, com en la història de l'art grec, des de l'art arcaic- amb el propòsit de repassar la seva presència en alguns autors de la Segona Sofística en paral-lel amb l'ús d'aquest motiu mític en diverses manifestacions artístiques d'aquest període, per provar d'establir alguna relació entre el relat textual i les mostres iconogràfiques.

\section{UNA FIGURA AMBIGUA}

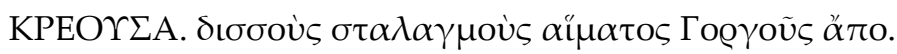

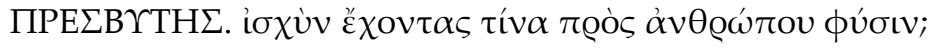

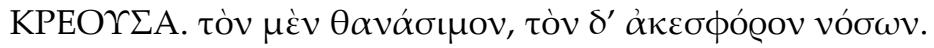

CREÜSA. Dues gotes de sang de Gòrgona.

VELL. Quina força tenen sobre la natura humana?

CREÜSA. L'una és mortífera, i l'altra, guaridora de malalties. ${ }^{1}$

Aquests versos d'Eurípides (Ion 1003-1005) sintetitzen la significació ambigua de la Gòrgona en el mite grec. Un monstre terrible infantat per la terra que, com explica Creüsa, pot alhora guarir i matar. A aquesta ambivalència s'hi suma la marginalitat que defineix la Gòrgona Medusa: habita els límits de la terra, sia a l'extrem occident, vora les Hespèrides, ${ }^{2}$ sia al nord, prop dels Hiperboris, ${ }^{3}$ sia als confins de Líbia, on regna una terra erma, ${ }^{4}$ sia encara a l'inframon. ${ }^{5}$ Aquesta marginalitat espacial denota alhora l'oposició entre civilització, identificada amb l'ordenació del món grec establerta en el mite després del triomf dels déus olímpics, i barbàrie, que cal vèncer i dominar per mantenir justament aquell ordre. ${ }^{6}$ Des d'aquesta perspectiva, no és casual que fos un heroi civilitzador com

\footnotetext{
${ }^{1}$ Les traduccions dels textos grecs i les fotografies d'aquest treball són de la meva autoria.

2 Hes. Th. 295-301.

${ }^{3}$ Pi. P. 10.30-50.

4 D.S. 3.52.4; Lucan. 9.619.

5 Verg. Aen. 6.390-396.

6 Vid. Vargas 2012.
} 
Perseu qui aconseguís decapitar Medusa, l'única mortal de les tres Gòrgones; ${ }^{7}$ ni que aquesta gesta fos acomplida sota la protecció d'Atena, ${ }^{8}$ deessa, per ella mateixa, sinònim de civilització, que simbolitza mitjançant l'apropiació del cap decapitat de Medusa com a trofeu inserit enmig del seu escut ${ }^{9}$ i com a ornament de la seva ègida, segons refereix també Eurípides (Ion 995-999):

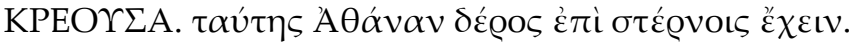

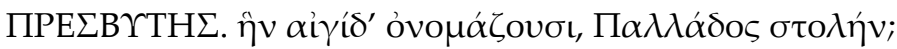

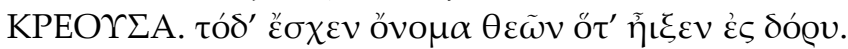

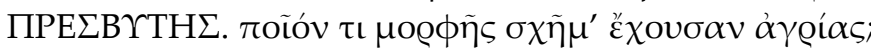

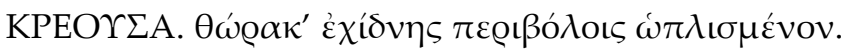
CREÜSA. D'ella, Atena en duu la pell sobre el pit.
VELL. La que anomenen ègida, vestidura de Pal-las?
CREÜSA. Aquest nom va rebre quan es va llançar al combat dels déus.
VELL. Quin aspecte té aquesta ferotge roba?
CREÜSA. Una cuirassa armada de revolts de serp.

La iconografia d'època arcaica i clàssica incideix, sobretot, en dos motius del mite: 1'aspecte horripilant de Medusa i el seu degollament a mans de Perseu. ${ }^{10}$ En aquest darrer cas, també l'obra plàstica implica relat, tracta de reproduir la narració mítica. Així, una bella mètopa (ca. $530 \mathrm{aC}$ ), procedent de l'anomenat Temple C de Selinunt (Sicília), està dominada per la figura central de Perseu, dempeus, mentre subjecta els cabells de Medusa amb la mà esquerra i amb la dreta talla el cap de la Gòrgona, el rostre de la qual és monstruós;11 Medusa,

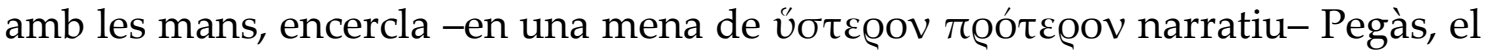
cavall alat que ha de néixer de la seva sang, un cop degollada. ${ }^{12} \mathrm{Al}$ costat de Perseu, Atena observa l'escena, disposada a intervenir per ajudar el seu protegit. ${ }^{13}$

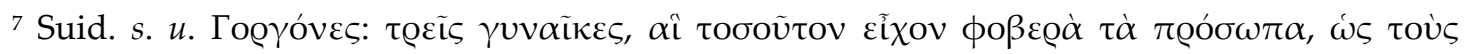

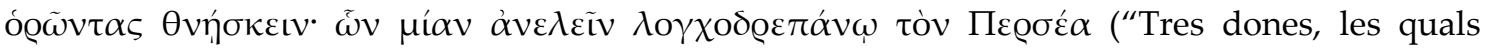
tenien un rostre tan espantós que mataven els qui les miraven; una de elles, Perseu l'occí amb una simitarra").

8 Neira 2015: 42: "Atenea habría sido la autora intelectual de la decapitación, mientras que Perseo su autor material". No debades, Гọүoфóvos ('matadora de la Gòrgona') és un epítet de la deessa (E. Ion 1478).

${ }_{9}^{9}$ Apollod. 2.4.3; Ov. met. 4.789-790.

10 Vid. Movellán 2014. El LIMC (IV.2: 163-207) ofereix un ampli recull iconogràfic sobre Medusa amb nombrosos testimonis artístics -procedents de manifestacions plàstiques diverses (ceràmica, arquitectura, mosaics...)- i també numismàtics, on es pot observar la representació d'aquesta figura mítica i la seva evolució des de l'època arcaica fins a l'època romana. Pellizer (1998-99) estudia en particular les metamorfosis de Medusa en la iconografia arcaica i clàssica.

${ }^{11}$ La mètopa es conserva al Museo Archeologico Regionale Antonino Salinas de Palerm; uid. Hurwit 1985: 294, fig. 127. Les extremitats inferiors de Medusa estan representades segons l'anomenat kneeling running, característic de l'art arcaic; uid. Sapienza 2017.

${ }^{12}$ Hes. Th. 280-281.

${ }^{13}$ El valor civilitzador del mite de Medusa és reforçat en aquesta mètopa per les altres dues que l'envolten: en una, Hèracles porta penjats dels peus els bandolers gegantins d'Eubea, els Cercops; en l'altra, el déu Apol-lo condueix la quadriga, flanquejat per Leto i Àrtemis.
} 
També la ceràmica en dóna mostres, d'aquest relat: per exemple, una pelike àtica de figures vermelles (ca. $450 \mathrm{aC}$ ), dita del pintor Polignot, ${ }^{14}$ on també Atena presideix l'escena de la decapitació de Medusa; o un lècit àtic ( $c a .500 \mathrm{aC}){ }^{15}$ en el qual s'identifiquen els personatges pel seu nom i, com en la mètopa, Pegàs apareix ja al costat d'una Medusa alada, com la de la pelike i com és habitual en la iconografia d'altres figures monstruoses com ara les Sirenes, les Erínies, les Harpies o l'Esfinx. ${ }^{16}$ En tots aquests casos, són destacats sempre els trets més ferotges de Medusa, que la converteixen en una figura quasi grotesca: uns grans ulls oberts que miren frontalment, i una boca, també oberta, amb ullals enormes. Així és representada en una terracota arquitectònica de Siracusa, del segle VII $\mathrm{aC}$, on, juntament amb aquests senyals inconfusibles de la seva fisonomia, es destaquen els atributs femenins de Gòrgona, que també subjecta a la mà dreta un petit Pegàs. ${ }^{17}$

Al costat de les mostres plàstiques que inclouen elements narratius del mite, en tot el període arcaic especialment, ${ }^{18}$ abunden també les representacions aillades del cap de Medusa com a motiu ornamental molt freqüent, no en els frisos o frontons dels temples -espais potser més adequats per al relat-, sinó en les antefixes que els coronen. D'aquesta manera, el rostre de la Gòrgona,

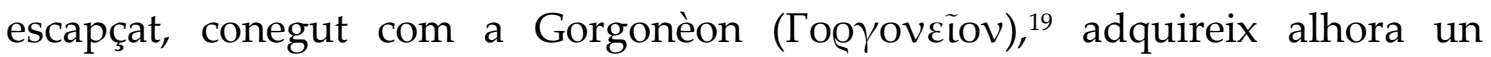
significat positiu: el seu caràcter màgic, d'amulet, propicia igualment el bé i, per tant, té una funció protectora.

\section{EL PODER DE MEDUSA}

El Gorgonèon és l'element plàstic que millor identifica Medusa desvinculant-la de la presència de Perseu, en el seu aspecte aterrador, esglaiador, capaç de fer, encara després de morta, que algú resti de pedra, però alhora també com a geni benefactor.

En la Descripció de Grècia Pausànias ressenya, arreu del territori grec, diversos espais ornats amb aquest motiu. Quan descriu l'estàtua criselefantina de Fídias, no passa per alt que "Atena està dreta, amb una túnica que li arriba als peus, i sobre el seu pit hi té el cap de Medusa tallat en ivori",20 i encara a

14 Aquesta peça es troba a New York, al Metropolitan Museum, núm. inv. 45.11.1; uid. LIMC IV.2: 183, fig. 301.

${ }^{15}$ Aquest vas també forma part de la col·lecció del Metropolitan Museum, núm. inv. 06.1070, de New York; uid. LIMC IV.2: 184, fig. 309.

16 Vid. Mayor Ferrándiz 2012; uid. LIMC IV.2: 188, fig. 346, per a la representació d'una esfinx amb cap de Gòrgona.

17 Aquesta mètopa es conserva al Museo Archeologico Nazionale de Siracusa; uid. LIMC IV.2: 181, fig. 275.

18 Vid. Marconi 2007: 214-217.

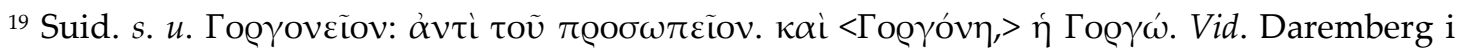
Saglio 1896: 1622-1629, on s'expliquen els diferents tipus d'aquesta representació.

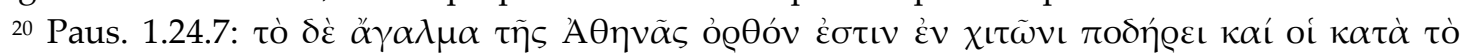

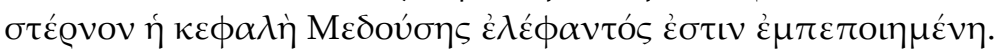


Atenes, el periegeta ubica un cap daurat de la Gòrgona Medusa, amb una ègida esculpida al voltant, al vessant meridional de l'Acròpolis en direcció cap al teatre de Dionís, sobre la muralla anomenada del Sud (Notíov). ${ }^{21}$ El motiu es repeteix a Argos, on Pausànias indica que a l'àgora, vora el santuari del Cefís, hi havia "un cap de Medusa tallat en pedra, que deien era obra dels Ciclops". ${ }^{22}$ També a Olímpia, al temple de Zeus, l'escut d'or ofrenat als peus d'una imatge de Nice (Níkๆ) -la Victòria que sol acompanyar Atena- "té esculpida la Gòrgona". ${ }^{23}$ La força espaordidora del Gorgonèon és manifesta en la història que Pausànias refereix sobre una sacerdotessa del temple d'Atena Itònia, a Coronea (Beòcia). Aquesta dona, Iodama, va entrar de nit al recinte sagrat i se li va aparèixer la dea, que duia sobre la túnica el cap de la Gòrgona Medusa; en veure-la, "Iodama es convertí en pedra". ${ }^{24}$ Igualment, Pausànias il-lustra el valor sobrenatural de Medusa amb una informació referent al santuari d'Atena Poliàtide, a Tègea (Arcàdia), quan explica per què el santuari és anomenat Èrima ('E $v \mu \alpha$, és a dir, 'defensa, protecció, baluard'). La ciutat de Tègea havia obtingut d'Atena el privilegi de ser inexpugnable per sempre, quan Àleu -el rei epònim d'Àlea, i posteriorment de tota l'Arcàdia- va rebre de la deessa un talismà perquè la ciutat fos inviolable: cabells de Medusa que ella mateixa va tallar del seu atribut. ${ }^{25}$

Aquests passatges de Pausànias vinculen el Gorgonèon a la divinitat, ${ }^{26} \mathrm{de}$ manera especial a Atena, també a Zeus, i eren visibles en espais públics, sobretot d'àmbit religiós, però això significa, per tant, que igualment estaven associats a l'estructura cívica de la polis i a l'ordre que la definia com a forma d'organització humana, la preservació de la qual restava garantit amb la protecció dels déus. En aquest sentit, és significativa la menció que Plutarc fa del Gorgonèon a la Vida de Temístocles, l'heroi de Salamina i, en conseqüència,

${ }^{21}$ Paus. 1.21.3. Aquesta muralla s'anomenava també Interior o Intermèdia perquè, de les tres muralles de l'Àtica, era la que se situava entre la del Nord o Exterior i la que conduïa fins a la

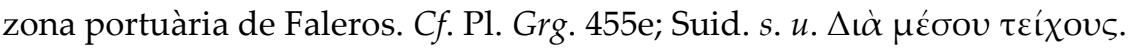

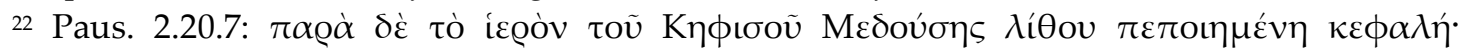

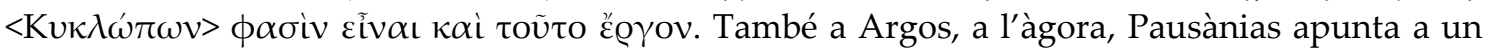
túmul de terra com el lloc on està depositat el cap de la Gòrgona Medusa, i aquesta identificació li dóna peu a relatar diverses variants sobre l'enfrontament entre Perseu i Medusa, indicant aleshores que, al costat del sepulcre de la Gòrgona, s'hi troba justament la tomba de Gorgòfone, filla de Perseu, i "per quina raó se li donà aquest nom, és evident tan bon punt el sents" (Paus.

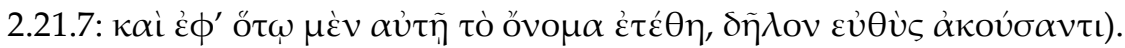

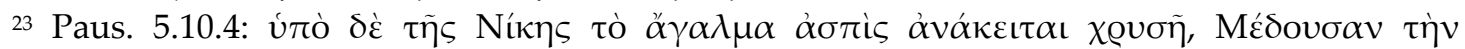

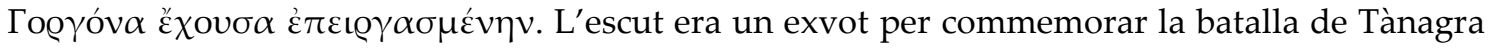
$(457 \mathrm{aC})$, segons la inscripció que reprodueix Pausànias.

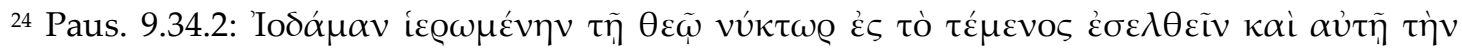

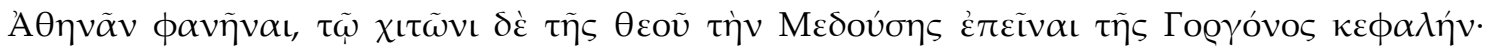

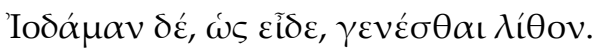

25 Paus. 8.47.6.

26 Pausànias vincula Medusa i Perseu en diverses ocasions: 1.22.7, 1.23.7, 2.27.2, 3.18.11, 3.17.3 o 5.18.5, per exemple. 
un nou "fundador" d'Atenes. ${ }^{27}$ Diverses fonts documenten la precària situació del tresor públic atenès abans de la decisiva batalla contra els Perses, però el de Queronea destaca, seguint l'atidògraf Clidem (FGrH 323 F 21 Jacoby), que la possibilitat d'equipar les naus no fou a expenses del Consell de l'Areòpag, com recull Aristòtil (Ath. 23.1), sinó un estratagema del general atenès: quan els atenesos es dirigien al Pireu per embarcar a les naus, constataren que el Gorgonèon havia desaparegut de l'estàtua de la dea; aleshores Temístocles, afanyós de recuperar-lo, va remoure cel i terra i va trobar amagada una gran quantitat de diners, "que fou confiscada i serví per aprovisionar la tripulació de les naus". ${ }^{28}$

\section{ÀMBIT PRIVAT}

Els mosaics d'època romana permeten constatar que Medusa continua essent una figura molt representada, sens dubte pel seu valor com a emblema de protecció. En alguns, tanmateix, s'hi pot observar un canvi significatiu: l'aspecte de Medusa no és tan terrible, ans fins i tot podria evocar més aviat el de "la donzella de belles galtes" que referia ja Píndar, ${ }^{29}$ tenint en compte la variant del mite segons la qual Medusa havia estat víctima del $\phi \theta o ́ v o \varsigma \theta \varepsilon \tilde{\omega} v$, en concret, de l'enveja d'Atena, i aquest fou el motiu de la seva transformació en un ésser d'aparença monstruosa. ${ }^{30}$

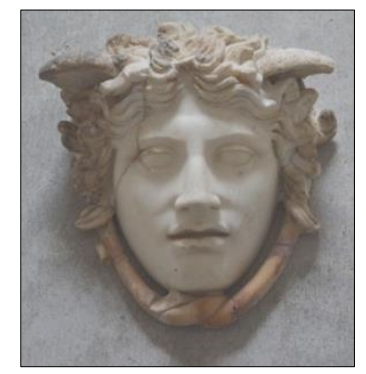

Fig. 1. Medusa Rondanini. Glyptothek München, núm. inv. 252.

La representació de Medusa als mosaics, tot i ser present també en espais públics com ara termes i banys, predomina, sobretot, en l'àmbit privat, en els paviments de domus i villae d'arreu de l'Imperi, tant en vestíbuls i zones de pas -així, per exemple, el mosaic de Perseu i Medusa al peristil de la casa dels sortidors de Conimbriga- ${ }^{31}$ com en estances principals, simbolitzant la protecció de la casa i dels seus habitants: Medusa espanta els enemics i allunya la mala sort. En aquests mosaics, enfront de la narració, preval el Gorgonèon com a peça central, sovint incrustat en patrons geomètrics d'efecte hipnòtic, destinats

\footnotetext{
27 Vid. Gómez 2017: 117-119.

${ }^{28}$ Plu. Them. 10.7. Aquesta anècdota recorda la faula del pagès i els seus fills (Aesop. 42 Perry).

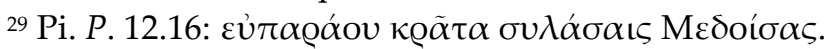

30 Apollod. 2.4.3; uid. MacKeon 1983.

${ }^{31}$ López Monteagudo 1990: 203-204.
} 
a recrear l'esguard desconcertant de la Gòrgona que mira fixament els hostes. Així ho testimonien mostres procedents de punts ben dispersos de la geografia imperial: de Perga (Turquia) a Sfax i Sussa (Tunísia), de Cirene a Cos, del Pireu fins a Tàrraco, d'Alexandria a la Lusitània, València, Sevilla o Palència (segle IV $\mathrm{dC}$ ). En aquesta forma artística, Medusa sol ser afaiçonada amb cara rodona, llavis carnosos, ulls grossos i enfonsats, un tipus de representació que recorda la famosa Medusa Rondanini (fig. 1), de mirada trista i malenconiosa, més bella i humanitzada que en les representacions habituals del Gorgonèon. ${ }^{32}$

Encara en l'àmbit privat, la pintura -tot i ser menor la documentacióofereix també testimonis de la pervivència del mite de Medusa. Per exemple, els frescos de Pompeia recorden tant el Gorgonèon, a guisa d'element decoratiu, com l'alliberament d'Andròmeda. Una d'aquestes mostres reflecteix sobretot el triomf de l'amor, atès que el cap de Medusa hi apareix sostingut per Perseu, per damunt dels caps de l'heroi i d'Andròmeda. ${ }^{33}$ En la seqüència del mite representa, per tant, el moment en què la filla de Cassiopea, ja alliberada, jeu amb Perseu; Medusa, protectora, acompanya la parella, després que la seva fulminant mirada hagi vençut la monstruosa criatura que mantenia presonera, encadenada, la bella jove, com Llucià explica en un dels Diàlegs marins (14.3), en què Tritó conversa amb les Nereides:

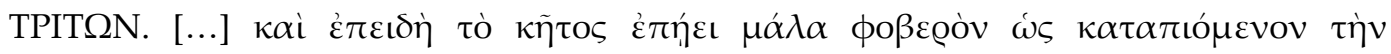

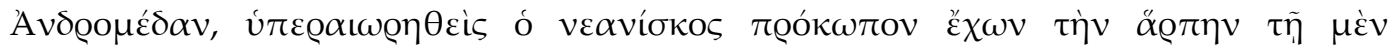

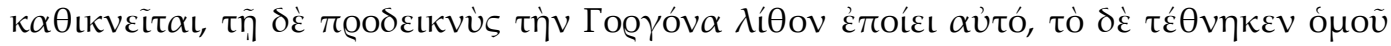

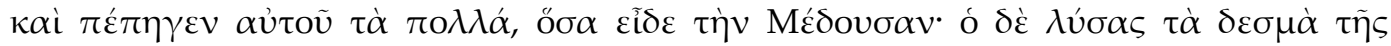

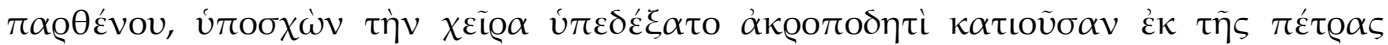

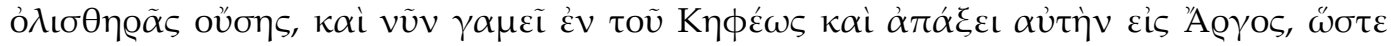

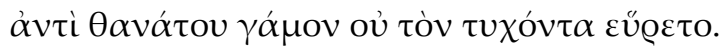

TRITó. [...] I quan el monstre, espantós, es llançava damunt Andròmeda per devorar-la, el jove, alçant-se per sobre, el colpeja amb la falç que branda en una mà, i, mostrant-li amb l'altra la Gòrgona, el converteix en pedra. Ara el monstre és ben mort, i la major part del seu cos, la que va veure Medusa, pedra. Ell aleshores deslligà les cadenes de la donzella, li allargà la mà i la subjectà mentre baixava de puntetes per la pedra que era relliscosa. Ara la pren per esposa al palau de Cefeu i després la durà a Argos, de manera que en lloc de la mort ha trobat noces, i no unes noces qualssevol.

El diàleg de Llucià narra la gesta de Perseu, l'enfrontament amb Medusa i amb el monstre marí, però es delecta a destacar el plàcid final de la història, en un to narratiu paral·lel al que reflecteix el fresc pompeià. També Higí recull en dues de les seves faules amoroses el mite de Perseu (fab. 63 i 64). En la dedicada a

${ }^{32}$ Belson (1980: 376) suggereix que la Medusa Rondanini ("as the first 'beautiful gorgoneion' occurring in the Greek art") és potser una còpia del gorgonèon de l'ègida de bronze dedicada pel rei selèucida, Antíoc IV (215-163 aC), i penjada com a element apotropaic al mur sud de l'Acròpolis, i, per tant, el seu original no seria una peça d'època clàssica.

${ }^{3}$ Es tracta del fresc Perseu i Andròmeda, de la dita Casa dels Diòscurs (Nàpols, Museo Archeologico Nazionale, núm. inv. 8998). Vid. Suárez Huerta 2006: 83-86. 
Andròmeda, focalitza l'atenció en la donzella presonera, exposada al monstre marí com a càstig per la insolència de Cassiopea, i en la manera com l'heroi Perseu l'alliberà. Al-ludeix al cap de la Gòrgona, però no en l'alliberament de la noia, sinó com a recurs emprat pel fill de Dànae contra el pare i el promès d'Andròmeda, quan aquests decidiren matar-lo, i contra Polidectes, qui l'havia criat a Serifos i arterosament volia també desfer-se del jove, en conèixer el seu valor. ${ }^{34}$ Higí, com Llucià en la conversa marina, ressalta sobretot el sentiment amorós de la jove parella i la gesta de Perseu, però a diferència del samosatenc no fa cap esment ni de l'enfrontament de Perseu amb la Gòrgona ni de la decapitació d'aquesta: es limita només a constatar l'hòrrida funció del seu talismà, que converteix en pedra els enemics de l'heroi.

Aquests autors subratllen la força terrorífica del Gorgonèon, malgrat que la vesteixen de relat heroic i amorós, en major o menor grau, però hi preval sempre la imatge del cap de Medusa com a emblema espaordidor. Des d'aquesta perspectiva, són particularment interessants les referències a Medusa que Llucià fa a De domo i a Imagines. La primera obra planteja la dificultat sobrevinguda a un orador quan declama en una sala magníficament ornada, perquè aleshores aquesta esdevé un autèntic rival i el públic, bocabadat, no escolta i només observa l'esplendor de l'espai físic, mentre que l'oratòria ha de "pintar" imatges "sense color, formes ni espai", més difícils de copsar en la seva nuesa. ${ }^{35}$

En una de les pintures descrites hi apareix Perseu matant el monstre marí (Llucià no explicita com) i alliberant Andròmeda, amb la qual -afirma- es casarà després. Però l'orador relata que aquest no és el motiu principal de la pintura, sinó un afegit al vol de Perseu envers el país de les Gòrgones. Llucià posa en valor l'habilitat del pintor a integrar molts elements en poc espai, i s'hi

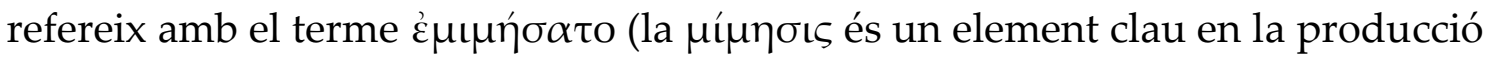
literària d'època imperial) per tal d'indicar com l'artista plàstic reprodueix la narració del mite (Dom. 22):

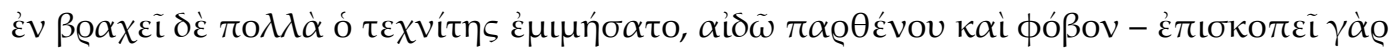

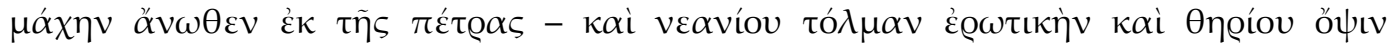

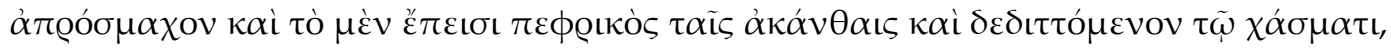

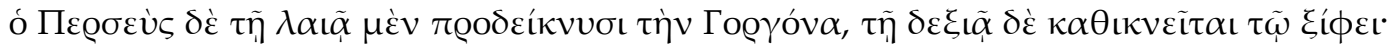

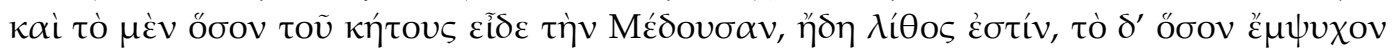

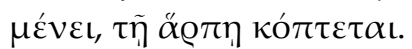

En poc espai l'artista ha representat molt de contingut: el pudor de la jove, la seva por (contempla la batalla de dalt estant, sobre un penya-segat), l'atreviment del jove impulsat per l'amor i la mirada invencible del monstre que avança eriçat d'espines $i$ aterrint amb la gola oberta. Perseu, però, amb la mà esquerra li mostra la Gòrgona i amb la dreta el fereix amb l'espasa. La part del monstre marí que mira Medusa ja és de pedra, i la part que encara respira és occida per la falç.

${ }^{34}$ Hyg. fab. 64.4.

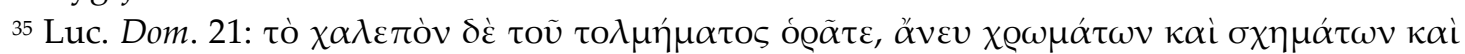

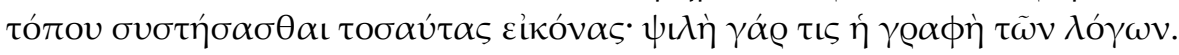


Aquesta sala inclou també una pintura referent a la mort de Medusa, atès que, després de la descripció d'altres pintures-narracions mítiques, l'orador deixa constància que Perseu reapareix -com indica l'adverbi $\pi \alpha ́ x \lambda \iota$ - en la gesta prèvia a la del monstre marí, és a dir, la decapitació de Medusa (Dom. 25):

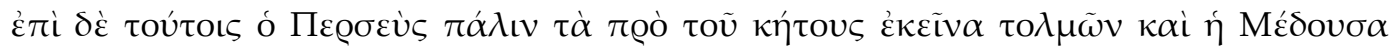

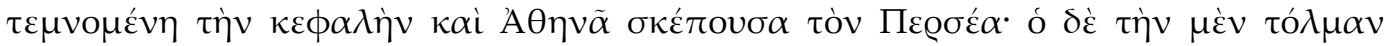

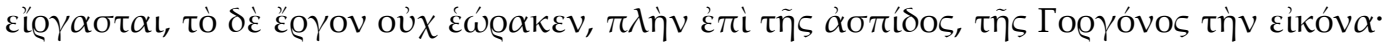

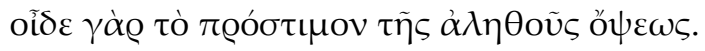

Després d'aquestes, Perseu altra vegada en la gesta prèvia a la del monstre marí: Medusa amb el cap tallat i Atena protegint Perseu. Ell ha acomplert la gesta, però no n'ha vist el resultat, només sobre l'escut la imatge de la Gòrgona. Coneix, sens dubte, el cost addicional de la vertadera mirada.

Així mateix, l'esment de la Gòrgona i de Medusa a l'inici d'Imagines mostra clarament que el samosatenc pot emprar-les com a termes metafòrics -gairebé antonomàstics- per denotar l'espant, la por o l'esglai davant d'una visió extraordinària. Licí -el personatge que inicia el diàleg- tot just ha vist una dona d'excepcional bellesa i reconeix que aquest espectacle admirable, però real, ha estat a punt de convertir-lo en pedra, com en el mite (Im. 1):

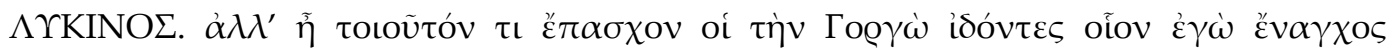

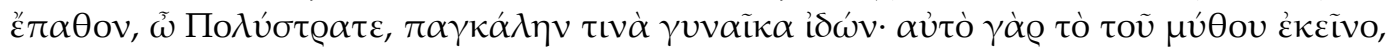

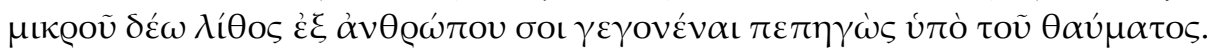

Licí. Sens dubte, Polístrat, els qui han vist la Gòrgona han tingut la mateixa impressió que jo mateix fa un moment quan he vist una dona molt bella. De fet, com en aquell mite, m'ha faltat poc per convertir-me d'home en pedra, colpit d'estupefacció pel prodigi.

El seu interlocutor, Polístrat, li demana més detalls i l'encoratja a descriure la dona per tal de compartir, mitjançant les paraules de Licí, l'efecte colpidor de la seva bellesa (Im. 1):

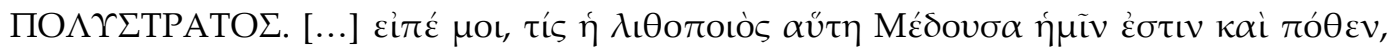

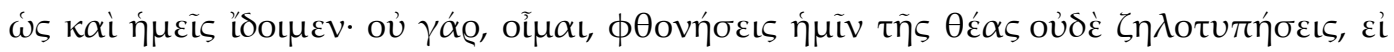

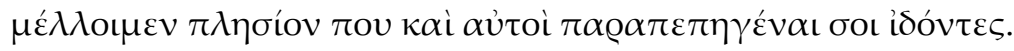

POLístRat. [...] Explica'm qui és aquesta petrificant Medusa i d'on ve, per tal que també nosaltres puguem veure-la. Crec que no ens envejaràs per l'espectacle, ni estaràs gelós, si també nosaltres, en veure-la, restem petrificats al teu costat.

Aquest mateix valor antonomàstic, tot i que amb un altre registre, és present per a Ateneu de Nàucratis (8.345 B) quan recorda com el poeta Hèdil (segle III aC) dedicà alguns epigrames als amants de la bona taula i, entre ells, es burlava de la golafre Clio, que identifica, precisament, amb Medusa, pel terror que provoca en veure-la menjar: 


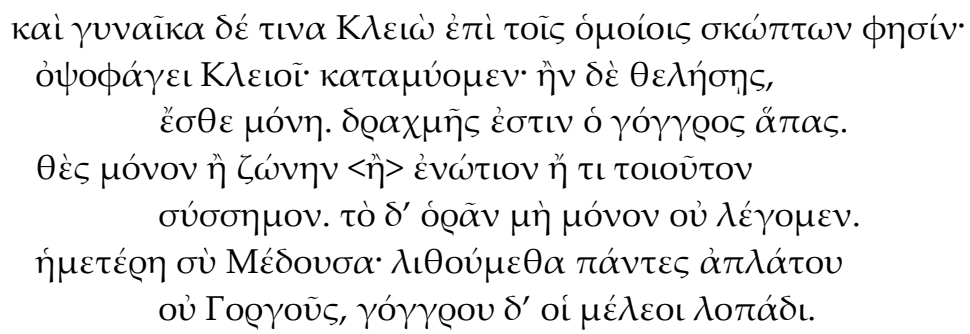

I de manera semblant feia mofa d'una tal Clio dient:

Afarta't, Clio: acluquem els ulls. I, si vols, menja sola. El congre sencer val una dracma.

Deixa només un cenyidor o una arracada o algun senyal semblant. Però de mirar-te, ni en parlem.

Ets la nostra Medusa. Restem tots de pedra, no per una monstruosa Gòrgona, sinó, malaurats, per una cassola de congre.

Aquest mateix to burlesc denota un fragment del comediògraf Antífanes ( $f r .164$ K.-A.) que cita un dels convidats en l'obra d'Ateneu (6.4.14-20), quan al magnífic banquet ofert per Larensi és servida una gran quantitat de peix exquisit. En aquest cas, l'objecte de la burla són els peixaters de Roma, els quals gaudien de tan mala fama com abans els de l'Àtica per vendre car un producte no sempre de bona qualitat:

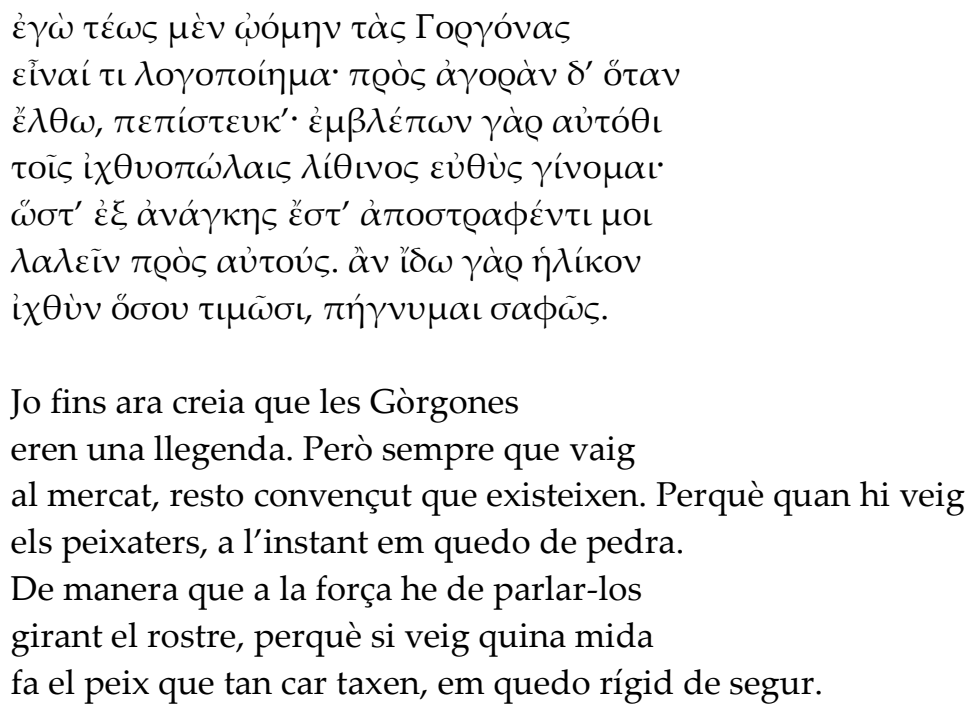

En un registre força diferent, la por i l'espant inherents al Gorgonèon són també recordats per Dió de Prusa, el sofista exiliat per Domicià, en un dels seus

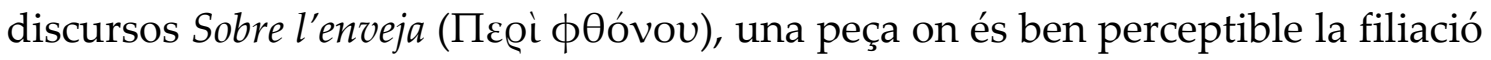
cinicoestoica de l'autor, puix que hi defensa la virtut i el seny com a valors primordials, enfront dels béns materials que hom s'afanya per aconseguir, i per tant exhorta a rebutjar l'elogi fàcil de la majoria, identificada amb els ignorants. D'aquesta manera, la seva referència a les Gòrgones apareix en un context en què la imatge terrorífica forma part d'una enumeració d'elements negatius, però que, en realitat, acostumen a ser només un foc d'encenalls, una aparença 
efímera i inconsistent que oculta la vertadera manera de ser, l'individu autèntic. ${ }^{36}$ Perquè un home prudent per naturalesa no persegueix riqueses ni elogis ni el reconeixement públic ni el benefici de reis i de pobles, ans és aquell que, sense

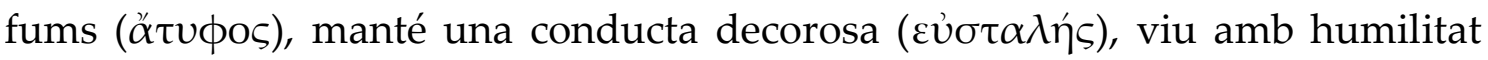
( $\tau \alpha \pi \varepsilon$ เvòs), obeeix la seva pròpia consciència i no cerca ornaments externs ni honors afegits, com és propi de "covards mercenaris que es posen plomes i plomalls, i Gòrgones sobre els escuts, i fan soroll amb llances petites, tot i que després fugen quan els sorprèn un perill insignificant". ${ }^{37}$

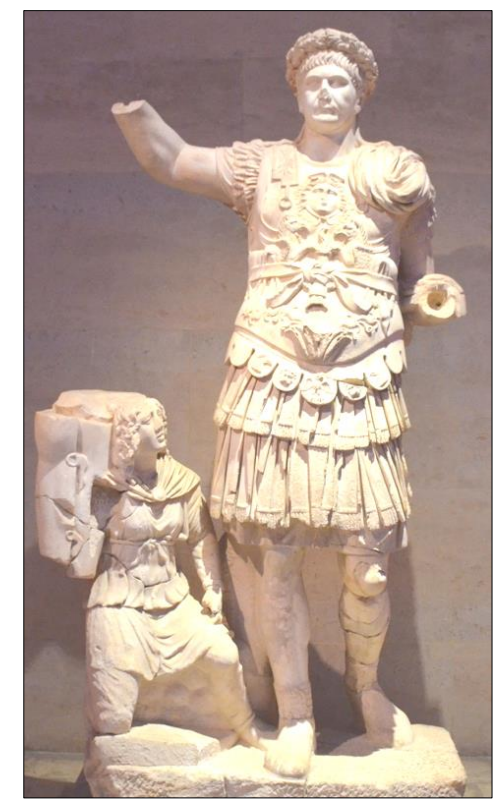

Fig. 2. Thoracata de l'emperador Trajà, Perga (s. II dC). Fethiye Muzesi.

\section{PODER PÚBLIC}

El text de Dió recorda encara l'ús iconogràfic que identifica el Gorgonèon amb el poder imperial: es tracta de la presència de Medusa en les anomenades thoracatae, o representacions de personatges romans amb indumentària militar, especialment en estàtues dedicades als emperadors, però el Gorgonèon es troba també en bustos esculpits. En tenim diversos testimonis, d'èpoques i dinasties distintes, arreu de l'Imperi, com a manifestació de lleialtat, però destaquen, per la seva profusió, les peces erigides als emperadors del segle II dC i procedents de les monumentals ciutats d'Àsia com Efes, Tlos, Afrodísia, Sida, Perga (fig. 2), entre d'altres. En totes aquestes mostres escultòriques és evident la connexió entre el cap de Medusa i el poder, i alhora, potser també, té relació amb el culte imperial -no estrictament religiós, sinó cívic i polític-, entès com l'aproximació

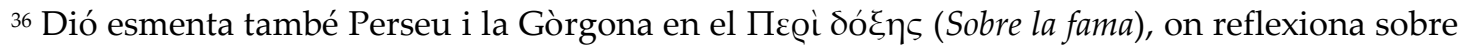
els perills de perseguir la fama i el bon nom, sovint sense merèixer-los; $c f$. D.Chr. 66.21.

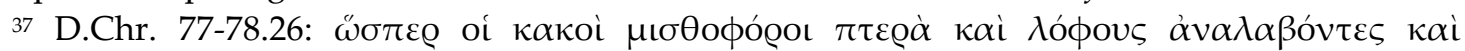

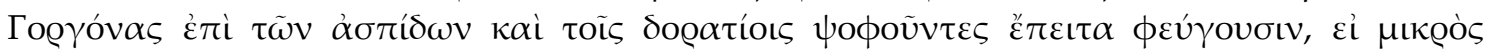

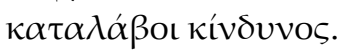


envers l'emperador i la seva autoritat de determinats honors reservats a la divinitat. ${ }^{38}$ Només Zeus -com mostra la magnífica estàtua del déu trobada al temple de Cirene- i Atena tenien el privilegi de dur el cap de Medusa a la seva ègida, el mateix emblema que reapareix a la cuirassa imperial, però també en altres elements arquitectònics vinculats a la figura de l'emperador. Per exemple, el temple d'Adrià, a Efes -d'ordre corinti, del segle II dC-, presenta com a relleu central en la decoració interior, precisament, un cap de Medusa (fig. 3). ${ }^{39}$ Aquest edifici és coetani del gran temple dedicat a Apol-lo i Atena a la ciutat pamfília de Sida, també del segle II dC: sota del seu frontó oest encara hi són visibles petites mètopes decorades amb Gorgonèons, una decoració semblant a la dels plafons de les llindes del temple de Mart de Mèrida (segle II dC). ${ }^{40}$ La mateixa funció estètica, més enllà de la protectora, tenia també el cap de Medusa al colossal temple d'Apol-lo a Dídima, on Adrià va reconstruir l'oracle. I, sens dubte, una de les millors manifestacions de la confluència entre Gorgonèon i poder es troba al fòrum severià de Leptis Magna, ornamentat amb grans clipeus esculpits amb caps de Medusa, ${ }^{41}$ del segle III dC, que ocupaven els espais entre les columnes del pòrtic (fig. 4). Estilísticament recorden el mosaic de la Medusa de Tàrraco, també del segle III $\mathrm{dC} .42$

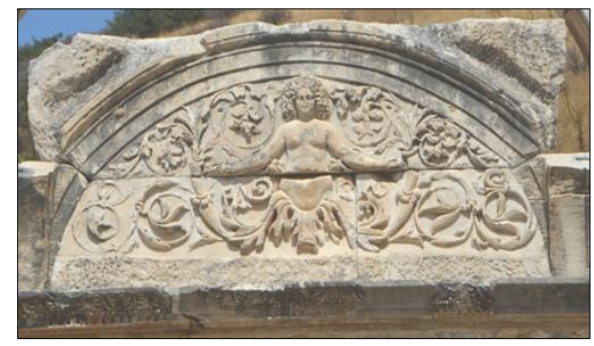

Fig. 3. Detall del temple d'Adrià (s. II dC). Efes.

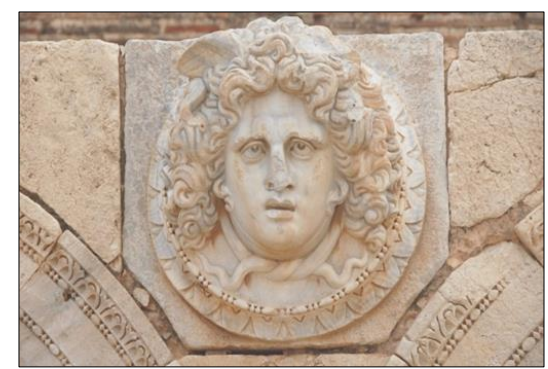

Fig. 4. Clipeus del fòrum severià (s. III dC). Leptis Magna (Líbia).

38 Evans 2011: 83: “Diverse institutions of emperor worship emerged organically from local environments, and allowed each people to negotiate their own particular relationship to imperial authority". Vid. Mestre i Gómez 2018.

39 Rocca 2018. Sobre aspectes cultuals, Jones 1993: 149-150; Burrell 2002-2003: 44-48.

40 Vid. León Alonso 1970: 182-184.

${ }^{41}$ Sèries de clipeus amb el cap de Medusa i amb el de Zeus Ammó decoraven també el pòrtic del fòrum municipal d'Augusta Emerita. Les peces, datades al segle I dC, es conserven al MNAR de Mèrida; uid. Peña 2009, 605-607, amb bibliografia anterior.

42 MNAT, núm. inv. 2921; uid. Navarro Sáez 1979: 166-168. 


\section{POST MORTEM}

Un nou ús iconogràfic del Gorgonèon prolifera a partir del segle II $\mathrm{dC}$, coincidint amb la consolidació de la inhumació, enfront de la incineració, com a pràctica sepulcral, sota el mandat d'Adrià. ${ }^{43}$ Així ho evidencia la profusió de sarcòfags que presenten com a element decoratiu el cap de la Gòrgona, recuperant-ne la funció protectora i apotropaica, en tutelar ara també els difunts al més enllà (fig. 5). La ciutat d'Afrodísia va ser un centre important de producció i difusió d'aquestes peces ${ }^{44} \mathrm{i}$, en paral-lel, les necròpolis de l'est de $l^{\prime}$ Imperi ofereixen un ric i abundós material, on Medusa apareix com a principal motiu decoratiu del sarcòfag, o bé en corona la part superior o frontal independentment que la resta de la decoració sigui de caire mitològic, faci referència a la vida quotidiana del difunt o a la seva posició social, inclogui escenes al-lusives a la mort $\mathrm{i}$ a les pràctiques rituals que hi són vinculades, $\mathrm{o}$ presenti, només, garlandes vegetals.

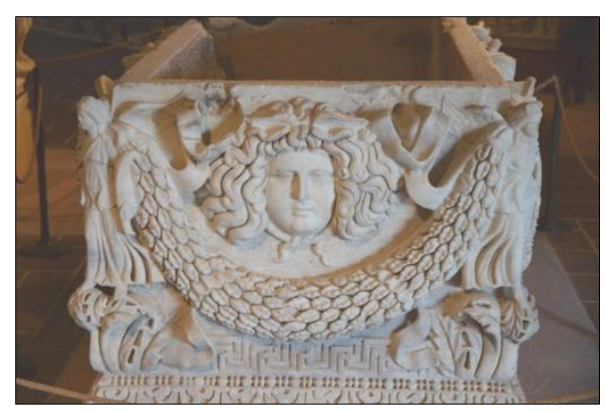

Fig. 5. Sarcòfag de la necròpolis de Hieràpolis (s. II dC). Hierapolis Arkeoloji Muzesi.

\section{A MANERA D'EPÍLEG}

En aquest recorregut que ha pretès agermanar paraules i imatges, no s'analitza amb detall el testimoni d'autors com Apol-lodor o com Ovidi, ${ }^{45}$ els quals, per la naturalesa de la seva obra, prioritzen el relat del mite de Perseu i Medusa, la narració de la disputa entre Atena i la bella Gòrgona, com i per què va ser transformada en un ser terrible, essent com era una bella donzella de formosos cabells. En canvi, hem volgut destacar com el Gorgonèon és un referent eficaç tant en els textos com en les representacions plàstiques per significar el valor de talismà que, amb força, exerceix poder i control sobre els enemics, com havia estat des de l'època arcaica. El mosaic de la Casa del Faune, a Pompeia, així ho revela: també Alexandre a la batalla d'Issos lluu el Gorgonèon com a preuat amulet. $^{46}$

\footnotetext{
${ }^{43}$ Clavería 2001: 22. Vid. també Toynbee 1996; Zanker i Ewald 2012.

${ }^{44}$ Vid. Rodà 2001: 53.

${ }^{45}$ Apollod. 2.3.2; 4.2-3; 5.12; Ov. met. 4.771-803; supra n. 9.

${ }^{46}$ El mosaic es conserva al Museo Archeologico Nazionale, núm. inv. 10020, a Nàpols.
} 
Contrasta, tanmateix, l'abundant representació iconogràfica dels primers segles de l'Imperi $^{47}$ amb la documentació textual, més aviat escassa, on, com hem assenyalat, Gòrgona i Medusa són emprades en els textos pel seu valor antonomàstic: l'esment del seu nom implica una forta càrrega semàntica. Tal vegada, però, la mateixa que l'ornamentació arquitectònica, les escultures o els mosaics fan entendre, atès que, si la literatura d'època imperial es caracteritza pel coneixement i la recuperació de la tradició literària, inclosos els mites que aquesta vehicula, tampoc les arts plàstiques no resten al marge d'aquesta recuperació del passat, de manera que la tria de Medusa, del Gorgonèon, és també per a les elits de l'Imperi una manera d'expressar poder o de cercar protecció, fins i tot, post mortem.

\section{BIBLIOGRAFIA}

BELSON, J. D. (1980), “The Medusa Rondanini: A New Look”, AJA, 84 (3), 373-378.

BurRELL, B. (2002-2003), "Temples of Hadrian, not Zeus", GRBS, 43, 31-50.

ClaverÍA NADAL, M. (2001), “El sarcófago romano. Cuestiones de tipología, iconografía y centros de producción", dins Noguera i Conde 2001: 19-50.

DAREMBERG, Ch. i SAGLIO, E. (1896), Dictionnaire des antiquités grecques et romaines d'après les textes et les monuments, vol. II.2, París, Hachette.

Evans, N. (2011), "Embedding Rome in Athens", dins Rome and Religion: A CrossDisciplinary Dialogue on the Imperial Cult, Brodd, J. i Reed, J. L. (eds.), Atlanta, Society of Biblical Literature, 83-97.

GÓmEz CARDÓ, P. (2017), “Una batalla, dos relatos: Temístocles en Salamina entre Heródoto y Plutarco", dins La (inter)textualidad en Plutarco. Actas del XII Simposio Internacional de la Sociedad Española de Plutarquistas (Cáceres, 8-10 de Octubre de 2015), Sanz Morales, M., González Delgado, R., Librán Moreno, M. i Ureña Bracero, J. (eds.), Càceres / Coïmbra, Universidad de Extremadura, 109-119.

HuRwit, J. M. (1985), The Art and Culture of Early Greece, 1100-480 B.C., Ithaca / Londres, Cornell University Press.

JONES, C. P. (1993), “The Olympieion and the Hadrianeion at Ephesos", JHS, 113, 149-152.

LEÓn AlOnso, M. P. (1970), “Los relieves del templo de Marte en Mérida”, Habis, 1, 181-197.

LIMC = Lexicon Iconographicum Mythologiae Classicae, vol. IV.2: Eros-Herakles, Munic / Zuric, Artemis, 1988.

López MONTEAGUdO, G. (1990), “El programa iconográfico de la Casa de los Surtidores en Conimbriga", ETF(hist), 3, 199-232.

MAcKeon, C. H. (1983), Iconology of the Gorgon Medusa in Roman Mosaic, Ann Arbor, University of Michigan [tesi doctoral].

MARCONI, C. (2007), Temple Decoration and Cultural Identity in the Archaic Greek World: The Metopes of Selinus, Cambridge, Cambridge University Press.

${ }^{47}$ L'espai limitat d'aquest treball, de caire filològic, no ha permès contrastar els textos amb més mostres iconogràfiques, especialment d'època hel-lenística. 
MAYOR FERRÁNDIZ, T. M. (2012), "Monstruos femeninos en la mitología griega", Revista de Claseshistoria, 287, 1-44 [en línia]. Disponible a: <claseshistoria.com/revista/2012/ articulos/mayor-monstruos-femeninos.pdf $>$ [consulta: 2 agost 2018].

Mestre RocA, F. i Gómez CARdó, P. (2018), "Llucià i el culte imperial", Anuari de Filologia: Antiqua et Mediaeualia, 8, 560-574.

MOVELLÁN LuIS, M. (2014), “Perseo ante Medusa. Imágenes de la lucha del héroe contra el monstruo", dins Realidad, fantasía, interpretación, funciones y pervivencia del mito griego. Estudios en honor del Profesor Carlos García Gual, Pérez-Jiménez, A. (ed.), Saragossa, Pórtico, 135-150.

NAVARro SÁEZ, R. (1979), Los mosaicos romanos de Tarragona, Barcelona, Universitat de Barcelona [tesi doctoral]. Disponible a: <hdl.handle.net/10803/31942> [consulta: 15 desembre 2019].

NEIRA, L. (2015), “Medusa en los mosaicos romanos: de la mirada que petrificaba a una mirada apotropaica", Ars \& Humanitas / Študije, 9.1, 32-57.

Noguera CELdRÁn, J. M. i CONDE GuerRI, E. (eds.) (2001), El sarcófago romano. Contribuciones al estudio de su tipología, iconografía y centros de producción, Múrcia, Universidad de Murcia.

Pellizer, E. (1998-99), "Storie di Medusa: varianti iconiche e varianti discorsive", Ítaca: Quaderns Catalans de Cultura Clàssica, 14-15, 19-35.

PeÑa JuRADO, A. (2009), "La decoración escultórica”, dins El foro de Augusta Emerita. Génesis y evolución de sus recintos monumentales, Ayerbe Vélez, R., Barrientos Vera, T. i Palma García, F. (eds.), Mèrida, CSIC, 583-621.

RoccA, S. (2018), "The so-called 'Temple of Hadrian' at Ephesus", Judaism and Rom [en línia]. Disponible a: <www.judaism-and-rome.org/so-called-\%E2\%80\%9Ctemplehadrian \%E2\%80\%9D-ephesus> [consulta: 1 febrer 2020].

RODÀ DE LlANZA, I. (2001), "Producción, materiales y circulación de sarcófagos en el Imperio Romano", dins Noguera i Conde 2001: 51-78.

SAPIENZA, A. (2017), "Lo knielauf schema. Analisi iconografica dei documenti numismatici e archeologici", Antesteria, 6, 63-75.

SuÁrez HuertA, A. M. (2006), "Perseo y Andrómeda. Un hito de la belleza ideal", Storia dell'Arte, 115, 77-102.

ToYnBeE, J. M. C. (1996), Death and Burial in the Roman World, Baltimore / Londres, The Johns Hopkins University Press.

VARGAS VÁzQUEZ, S. (2012), “Atenea y Medusa. Entre civilización y barbarie”, dins Civilización y barbarie. El mito como argumento en los mosaicos romanos, Neira, L. (ed.), Madrid, Creaciones Vincent Gabrielle, 69-82.

ZANKER, P. i EWALD, B. C. (2012), Living with Myths: The Imagery of Roman Sarcophagi, Oxford, Oxford University Press. 